\title{
Simulation of Spray Injection in the Pressurizer Using RELAP5
}

\author{
S. Dibyo and Susyadi \\ Center for Nuclear Reactor Technology and Safety, National Nuclear Energy Agency, \\ Puspiptek Area Serpong, Tangerang 15314, Indonesia
}

\section{ARTICLE INFO}

\section{Article history:}

Received 17 March 2016

Received in revised form 07 February 2017 Accepted 10 May 2017

\section{Keywords:}

Sprayer

Injection

Simulation

Pressurizer

RELAP5

\begin{abstract}
A B S T R A C T
A modeling research using RELAP5 to assess the pressurizer of a pressurized water reactor (PWR) power plant has been performed. The heater and water injection systems in the pressurizer system of the PWR are of great importance for system pressure control. The heater is designed to increase the pressure while the water sprayer injection is to perform depressurization. Most of studies conducted in the past mainly focused on determining the effects of nozzle spray design and droplet size using testing loops. The purpose of this simulation is to analyze the spray injection flow rate against the pressure characteristics of the pressurizer using RELAP5. Through this approach, the optimum injection flow rate of full scale plant pressurizer can be analyzed. The parameters investigated are pressure and temperature. In RELAP5, the pressurizer tank was modeled with six volume nodes and the heater was modeled by using heat structure. In the model, the sprayer takes water from the cold leg to inject it into the top of tank region. The results showed that the mass flow of about $4 \mathrm{~kg} / \mathrm{s}$ is the most effective value to limit pressure in the pressurizer to below 15.7 MPa. However, the flow rates of $8 \mathrm{~kg} / \mathrm{s}$ and more cause overpressure. This simulation is useful to complement the data related to the water flow rate injection systems of the pressurizer.
\end{abstract}

(C) 2017 Atom Indonesia. All rights reserved

\section{INTRODUCTION}

In many parts of the world, nuclear power plants have been used to generate electricity. In a nuclear power plant type known as the pressurized water reactor (PWR), the pressurizer plays an important role for controlling the pressure of the primary coolant system. It maintains the core in a subcooled level, thus preventing the fuel from being exposed to hazardous situations [1,2]. This equipment is installed in the hot leg. The pressurizer operates with a mixture of steam and water in equilibrium. At any certain temperature, the pressurizer will have a certain water vapor pressure as well. When the primary loop pressure changes, the primary cooling water flow through the surge pipe changes the pressurizer's pressure [3]. Changes in the pressurizer's pressure initiates the control system's

${ }^{*}$ Corresponding author.

E-mail address: sukdibyo@batan.go.id

DOI: https://doi.org/10.17146/aij.2017.455 action so that the desired pressure can be maintained at a certain set point [4].

The pressure control is carried out by heaters and sprayers. In this system, the heater is an important component to raise pressure. The heater is turned on to increase the temperature and pressure. Meanwhile, water injection from the cold leg is used to spray the top of pressurizer to decrease the temperature and pressure through condensation. The system is protected from over pressurization using relief valves. If the pressure rises too high, the valves will automatically open to vent the steam to the atmosphere. After the pressure drops low enough, the relief valves automatically reclose.

The pressurizer is a vertical metal cylinder that is partially filled with water and connected to the hot leg. During normal operation, several heaters continuously operate to compensate a continuous intermittent activation of sprayer and also for heat losses to the environment.

Most of studies conducted in the past mainly focused on the measurement of the angle spray, 
nozzle spray dimension, and droplet size using testing loop and swirling nozzles experiment [5]. Spraying systems have been widely used in nuclear energy engineering, such as in the pressurizer or in the containment. Xiangbin Li et al. have carried out the scaling analysis of coolant spraying process in automatic depressurized system [6]. The heat transfer of spray droplets also have been investigated by Jo, Lee, and Shin [7]. In the Maanshan nuclear power plant, Taiwan, during normal operating condition (using one backup heater), the effect of a low fluid flow rate of $0.126 \mathrm{~kg} / \mathrm{s}$ sprayed into the pressurizer was investigated by Y.H. Cheng et al. [8]. Detection and estimation of sensor drifts using Kalman filters with a demonstration on a pressurizer was done by S. Cho and J. Jiang [9]. These above studies did not analyze the optimum injection mass flow rate into the pressurizer.

The purpose of this simulation is to analyze the spray injection flow rate after all heaters turn on against the pressure characteristics of the pressurizer. Therefore, the optimum injection flow rate of pressurizer can be obtained. The data of power plant scale of pressurizer is used. The main parameters of the pressurizer based on various injection flow rate can be analyzed using the model. In order to perform the analysis of temperature and pressure changes in the pressurizer, RELAP5 code is applied. RELAP5 as a validated code can be used to analyze the characteristics of reactor coolant system (RCS), and also can analyze the transient of hydrodynamic conditions for the mixed water vapor and noncondensable fluid. This computer code is provided with the equation of mass, energy, and momentum. Problems of hydrodynamics and heat transfer in the thermalhydraulic system can be solved with this code. Concisely, the main parts of the pressurizer model are the components of pipes, a single volume, junctions, and heat structures.

\section{THEORY}

\section{Pressurizer system}

In the primary cooling system, hot water from the reactor enter each of the steam generators through pipes called the hot leg. The surge line is connected to the hot leg to flow the coolant into and out of the pressurizer during thermal expansions and contractions. After coolant water leaves the steam generator, it returns to the reactor vessel through the pipes of the cold leg. The pressurizer is equipped to control the pressure of the reactor system. The pressure control is carried out by using the heater and sprayer in the pressurizer tank [10]. Inside the pressurizer, its cylinder is partially filled with water as shown in the simple scheme in Fig. 1. The electric heater mounted is immersed in the bottom head.

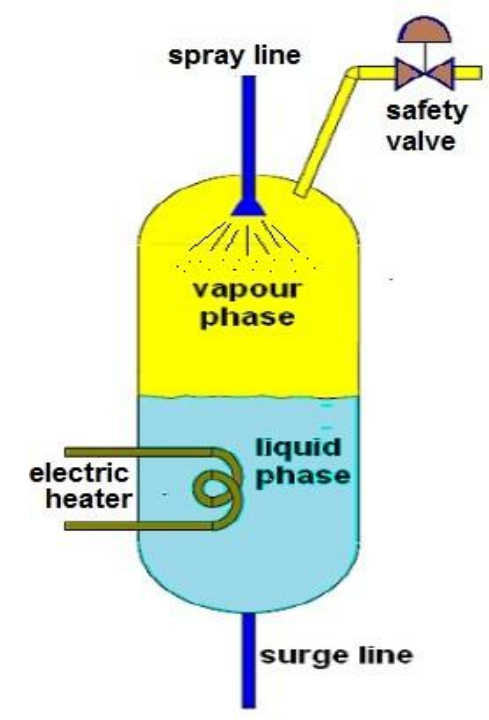

Fig. 1. A simple scheme of the pressurizer.

The spray line nozzles and the automatic depressurization and safety valve connections are located in the top head of the pressurizer tank. The spray flow is modulated by automaticallycontrolled, air-operated valves. The spray valves can also be operated manually from the control room. Meanwhile, the safety valves automatically open at a preset overpressure.

The pressurizer is a vertical, cylindrical tank with hemispherical top and bottom heads, where liquid and vapor are maintained in equilibrium under saturated conditions for pressure control of the reactor coolant system during steady-state operations and transients. During the steady-state operation at 100 percent power, approximately 60 percent of the lower part pressurizer volume is filled with water and 40 percent is steam [11]. At normal condition, the pressure range is about 15.4 MPa-15.7 MPa [12]. This is in accordance with the system temperature of about $602 \mathrm{~K}$. Therefore, the pressurizer should maintain reactor system at the subcooled conditions. So, the boiling conditions can be avoided. The temperature of main spray is nearly equal to the cold leg temperature of about $553 \mathrm{~K}$.

In the AP1000 pressurizer, the steady-state heat losses indicates that a heater capacity of about $166 \mathrm{~kW}$ is sufficient to maintain saturated conditions. The heaters are located in the liquid phase and grouped into a control group and backup groups. One group alone can maintain control over RCS pressure and subcooling. 


\section{RELAP5 code}

The RELAP5 code is a computer program widely used to analyze the overall light water RCS including its thermal-hydraulic response, control system interactions, reactor kinetics, and transport of noncondensable gases. It was originally designed to analyze complex thermalhydraulic interactions that occur during either postulated large or small break loss-of-coolant accidents (LOCAs) in PWRs. Besides calculating the behavior of a RCS during a transient, RELAP5 can also be used for simulating a wide variety of thermalhydraulics systems $[13,14]$.

The code is developed at the Idaho National Engineering Laboratory (INEL) under the sponsorship of the Office of Nuclear Regulatory Research of the U.S. Nuclear Regulatory Commission (NRC). In RELAP5, the basic equations for the liquid vapor system is a two-fluid model that consist of mass, momentum, and energy equations. In the case of two-phase flow process (such as in the pressurizer), equation (1) is used to define the vaporization (or condensation) rate of water [15] :

$$
\tau_{i g}=\frac{H_{i g}\left(T^{s}-T_{g}\right)+H_{i f}\left(T^{s}-T_{f}\right)}{h_{g}^{*}-h_{f}^{*}}
$$

Where,

$$
\begin{gathered}
H_{i g,} H_{i f}: \begin{array}{l}
\text { g gas-to-fluid interface heat transfer } \\
\text { coefficient per unit volume }
\end{array} \\
\begin{aligned}
& \text { saturation temperature (it is assumed that } \\
& \text { vapor occurs at saturation) }
\end{aligned} \\
T_{g}, T_{f} \quad: \text { temperature of gas and fluid } \\
h_{g}{ }^{*}, h_{f}{ }^{*}: \text { enthalpy of gas and fluid }
\end{gathered}
$$

\section{METHODOLOGY}

\section{Pressurizer model for RELAP5}

The nodalization of RELAP5 is developed from a previous model [16]. To calculate the thermalhydraulic behavior of pressurizer, the sprayer model is added. The pressurizer model is constructed of the generic hydraulic components of RELAP5, including the pipe, junction, heat structure and the other components input data. As shown in Fig. 2, the hot leg with a water volume of $243.5 \mathrm{~m}^{3}$ is applied using a single volume (snglvol-No.106). The surge pipe is represented by a pipe component (p-152). In the pressurizer tank (p-140) there is a heater that is represented as a component of heat structure. The tmdpvol-100 is the volume of relief tank that connected to the system relief valve (v-103) for depressurization purposes. Meanwhile, a piping from the cold leg (tmdpvol-700) is connected to the pipe of p-300 and spray cooler water in the top of the pressurizer.

In the simulation model, data of tank component (p-140) uses the control word of 2 for the Card Number ccc1201. In these control words, the data entered in the tank components consists of the pressure and the void fraction at equilibrium condition.

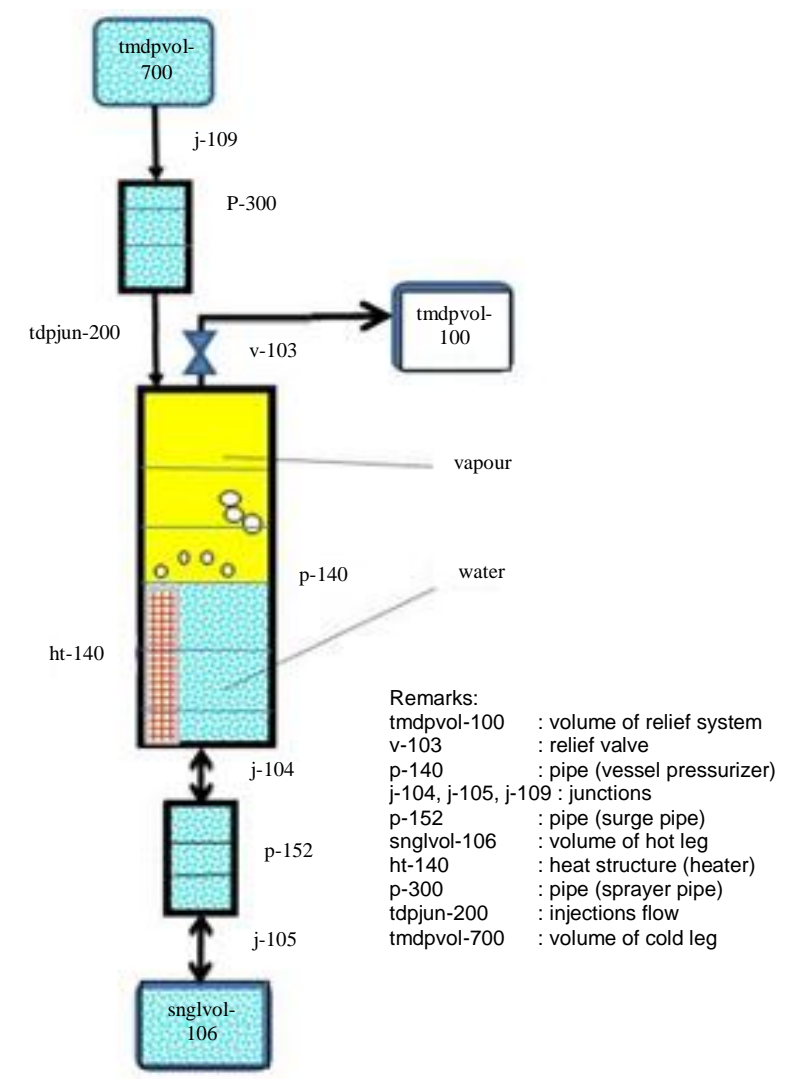

Fig. 2. Nodalization model.

The whole model are consist of 3 pipe volume component, 1 heat-structure, 1 single volume, 4 single-junction, 1 valve and 3 time dependent volume (tmdpvol). The tank components of pressurizer are divided to be 6 nodes. It's assumed that the water is filled to $1 / 2$ of tank height. In addition, the tank assumed to be isolated perfectly so that heat transfer in the walls ignored. Based on the model has been developed by using RELAP5, so the input-deck is created.

\section{Simulation}

The first step in modeling is to identify the pressurizer data, including its size and dimension parameters. The pressurizer of AP1000 is based on a proven design. Therefore, the geometry parameter and additional data required were already chosen for 
this simulation. The next step, running of RELAP5 at steady state, was conducted, and transient simulation was then also carried out. The extreme assumption was made that the whole heater group capacitiy was turned on. The heater group parameters are shown in Table 2. In the simulation, all heaters were turned off just before the sprayer began to open. The sprayer was activated by the pressure setpoint of 15.5 MPa. Afterward, coolant was sprayed into the pressurizer with a mass flow rate of $0.5 \mathrm{~kg} / \mathrm{s}$ to $10 \mathrm{~kg} / \mathrm{s}$. The parameters of pressure, temperature and surge flow rate were investigated. Meanwhile, several other parameters regarding the pressurizer behavior was not considered. Schematically, the method to simulate the pressurizer characteristics of pressure and temperature with regard to spray injection is shown in Fig. 3.

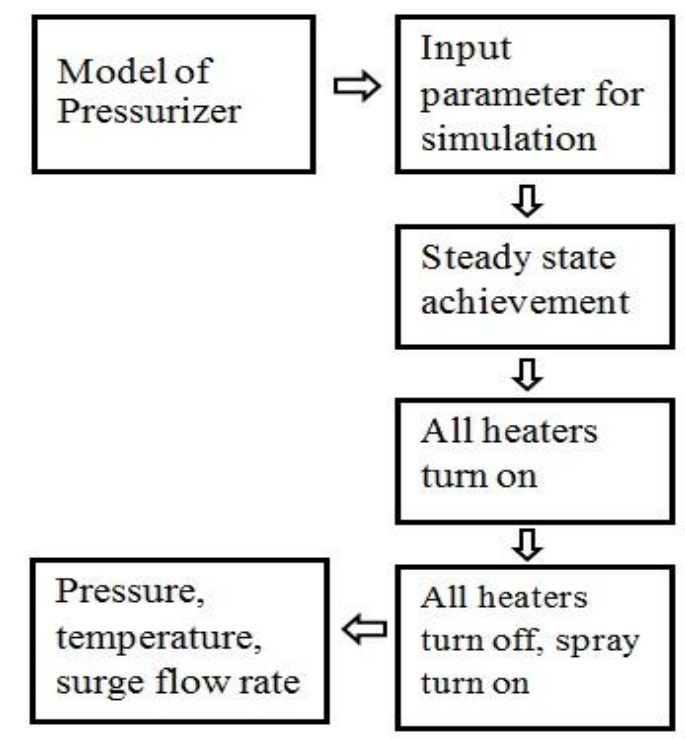

Fig. 3. Scheme of modeling.

Table 1. Parameters of the pressurizer.

\begin{tabular}{|c|c|c|}
\hline No & Parameter & Values \\
\hline 1 & $\begin{array}{l}\text { hot leg volume total+vol. } \\
\text { pressurizer, } \mathrm{m}^{3}\end{array}$ & 271.842 \\
\hline 2 & water volume of pressurizer, $\mathrm{m}^{3}$ & 28.317 \\
\hline 3 & total volume of pressurizer, $\mathrm{m}^{3}$ & 59.465 \\
\hline 4 & spray line diameter, $\mathrm{m}$ & $0.060-0.100$ \\
\hline 5 & hot leg diameter, $\mathrm{m}$ & 0.7874 \\
\hline 6 & surge line diameter, $\mathrm{m}$ & 0.4572 \\
\hline 7 & surge line long, $\mathrm{m}$ & 6.73 \\
\hline 8 & pressurizer tank diameter, $\mathrm{m}$ & 2.54 \\
\hline 9 & pressurizer tank length, m & 12.78 \\
\hline 10 & pressure range, $\mathrm{MPa}$ & $15.4-15.7$ \\
\hline 11 & $\begin{array}{l}\text { pressurizer spray valves (begin } \\
\text { to open) }\end{array}$ & 15.5 \\
\hline 12 & wall roughness, $\mathrm{m}$ & $4 \times 10^{-6}$ \\
\hline
\end{tabular}

Table 2. Pressurizer heater group capacity.

\begin{tabular}{clc}
\hline No & Heater group & Power $(\mathrm{kW})$ \\
\hline 1 & Control group & 370 \\
2 & Backup group A & 245 \\
3 & Backup group B & 245 \\
4 & Backup group C & 370 \\
\hline
\end{tabular}

The pressurizer parameters used as simulation input data are shown in Table $1[14,17,18]$. The data includes dimensions and operating data (set point, temperature, pressure). Wall roughness is also added. Furthermore, Table 2 shows the data of heater group capacity that is used to raise the pressure of pressurizer [18].

\section{RESULTS AND DISCUSSION}

The simulation to observe the effects of spray flow rate against the characteristics of pressure behavior in the pressurizer by using RELAP5 has been successfully carried out. The steady state calculation was conducted first. The trasient simulation was started from the heater that heated the water up in the pressurizer of $15.15 \mathrm{MPa}$, resulting in the increasing pressure that causes the volume of water to expand in the pressurized tank. As the pressure should not exceed the boundary conditions of $15.7 \mathrm{MPa}$, the injection of sprayer system must be turned on.

In this simulation, the relief valve performance simulation was not performed. This was because the tank relief system that was modeled by tmdp vol-100 is only open when an overpressure of 16.0 MPa is reached [16]. In other words, the emergency condition will not occur at normal transient; therefore, no safety relief valve will open.

In RELAP5, the request to start the sprayer injection was made through the trip card variables of input deck. In order to get the values of the parameters on the effect of injection to the temperature and pressure of pressurizer has been done from the Minor Edit Requests Card. Figure 4 shows the simulation results, with the curves indicating the effect of spray flow rate against the pressure on the top region of the pressurizer. The pressure behavior shows that if the mass flow injection is about $2 \mathrm{~kg} / \mathrm{s}$, the limit value of $15.7 \mathrm{MPa}$ is exceeded and the pressure is reduced back to less than 15.7 $\mathrm{MPa}$. In addition, at the normal operating condition, when one backup heater is used, spray flow rate is only $0.126 \mathrm{~kg} / \mathrm{s}$ as described by Y.H. Cheng [8]. Likewise, the spray flow rate 
based on best estimate of steady state operating data of AP1000 is around of $0.25 \mathrm{~kg} / \mathrm{s} \mathrm{[18].} \mathrm{In} \mathrm{this}$ simulation, after all heater turned on, the mass flow rate of about $4 \mathrm{~kg} / \mathrm{s}$ was found as the optimum injection rate to successfully decrease the pressure and the most effective value to keep the pressure so that the upper limit value of operation pressure range $(15.7 \mathrm{MPa})$ would not be reached. However, for the next simulation that used mass flow spraying $8 \mathrm{~kg} / \mathrm{s}$ or more indicated an ineffective overflow injection. This can be seen from an upward trend of pressure due to excessive pressure by the unmixed water injection in the tank. On the other hand, there is spray-condensate mixture that reaches saturation temperature before entering the liquid phase. Meanwhile, it is well known that the latent heat exchange is a major factor for the cooling when a large number of droplets are injected into the ambient gaseous phase [19].

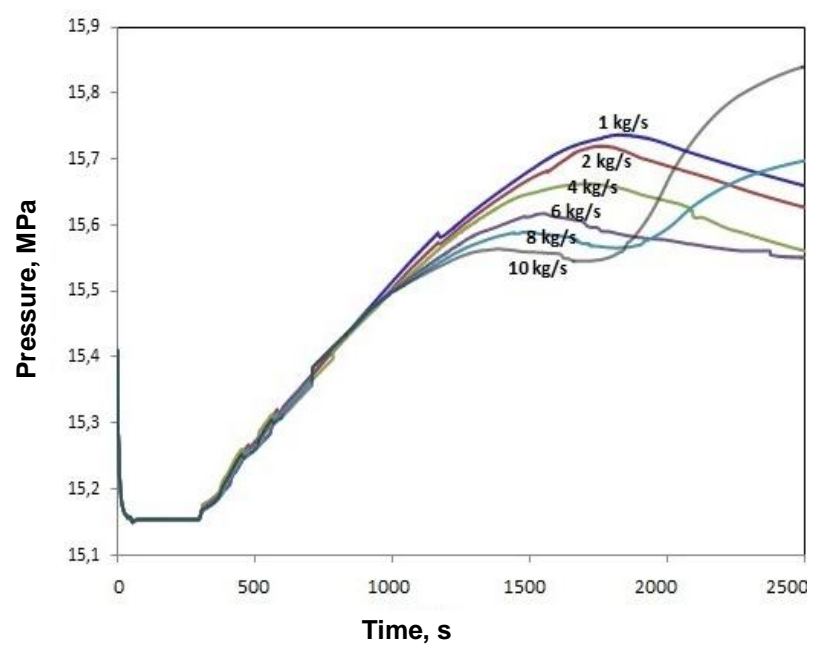

Fig. 4. Curve of tank pressure.

Figure 5 shows the optimum curve of pressure and temperature under a $4 \mathrm{~kg} / \mathrm{s}$ spraying of water from cold leg. Simulation results suggest that that flow rate of spraying is the ideal spraying conditions compared with other flow rates. As written in the previous description, the heater is submerged in saturated water at the bottom of tank and gives heat to raise the temperature. Stopping heater operation followed by activating the sprayer will keep the pressure to not more the limit value of 15.7 MPa. Pressure decrease as consequence of the latent heat exchange occurred after 670 seconds since cold water injection. However, the pressure in the pressurizer is not reduced instantly due to the impact of hot water from surge line. The effect of water injection from the cold leg can be seen from the temperature curve that is lower compared with the temperature of the center region.

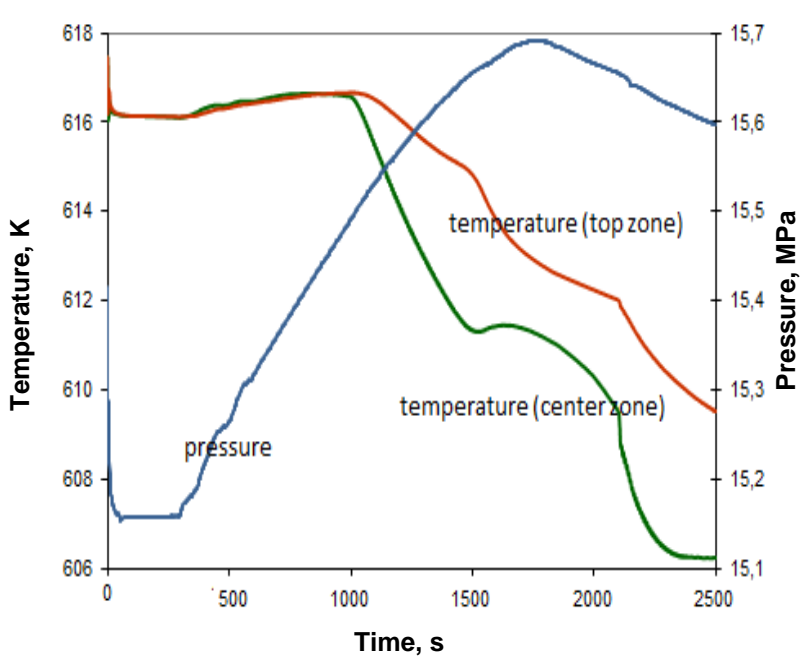

Fig. 5. Curve of pressure and temperature at $4 \mathrm{~kg} / \mathrm{s}$ spray mass flow rate.

To complete the characteristic data of simulation result for the water mass flow rate injection of $4 \mathrm{~kg} / \mathrm{s}$, the flow conditions in the surge pipe is displayed in Fig. 6. In this transient, there was a flow rate fluctuation in the surge pipe, as also reported by Ref. [20]. As the heater turned on, the flow in surge pipe moved toward the hot leg and oscillated in the range of about $2 \mathrm{~kg} / \mathrm{s}$. Furthermore, the in-surge flow would occur when the spray injection of cold water was conducted.

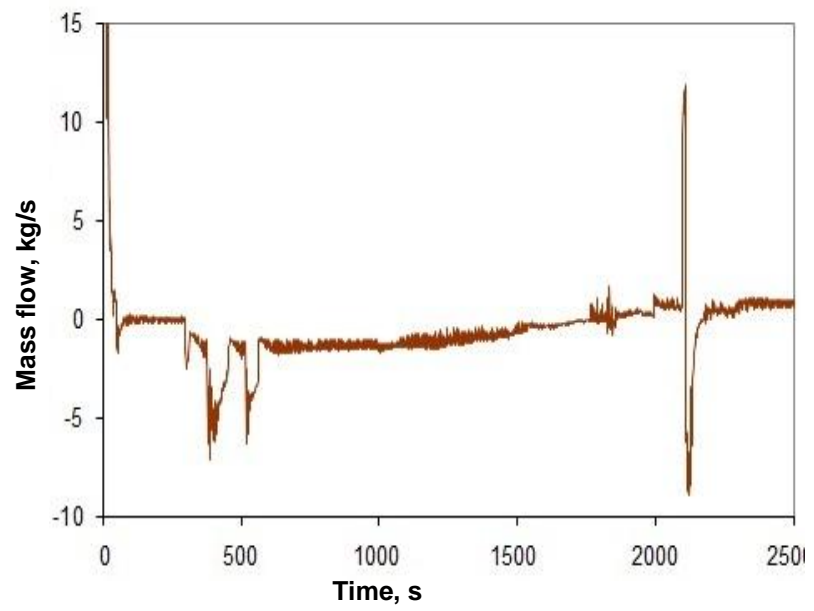

Fig. 6. Curve of surge mass flow rate .

\section{CONCLUSION}

The simulation has been done by using RELAP5 as the investigation code. The results show that the spray mass flow effects dominated the pressure parameter of the pressurizer system during transient simulation. In the mass flow rate of about $4 \mathrm{~kg} / \mathrm{s}$, the injection successfully decreased the pressure and the limit value was not exceeded. When the mass flow rate spraying reached $8 \mathrm{~kg} / \mathrm{s}$ or 
more, the simulation indicated overflow injection. The simulation is useful to assess the role of sprayer injection flow rate although its results still need to be compared with experimental results. Further simulations of power plant scale pressurizers, including the effects of spray flux distribution, shape of sprayer, and nozzle size, are some of the important agenda that can be followed in the future. The simulation conducted is expected to complement the data related to the water flow rate injection systems.

\section{ACKNOWLEDGMENT}

The authors would like to acknowledge the Reactor Physics and Technology Division, Center for Nuclear Reactor Safety and Technology, BATAN, and DIPA funding for the support provided for completing this research.

\section{REFERENCES}

1. S.K. Moghanaki and M. Rahgoshay, Appl. Mech. Materials 423 (2013) 1444.

2. M.A.B. da Silva, C.A.B. de O. Lira and A.C. de O. Barroso, Prog. Nucl. Energy 53 (2011) 1181.

3. S. Qiaoa, H. Gua and H. Wanga, Ann. Nucl. Energy 73 (2014) 211.

4. S. Bakhri, J. Nucl. Reactor Tech. TDM 16 (2014) 149. (in Indonesian).

5. Z. Lan, D. Zhu, W. Tian et al., Ann. Nucl. Energy 63 (2014) 215.

6. X. Li, M. Zhang, Z. Du et al., Ann. Nucl. Energy 72 (2014) 350.
7. J.C. Jo, S.K. Lee and W.K. Shin, KSME Journal 5 (1991) 130.

8. Y.H. Cheng, J.R. Wang and H.T. Lin, Nucl. Eng. Des. 239 (2009) 2343.

9. S. Cho and J. Jiang, Nucl. Eng. Des 242 (2012) 389.

10. M. Yu, X. Zhao, Y. Niu et al., Adv. Materials Res 860 (2014) 2409.

11. G.D. Zhang, X.H. Yang, X.L. Ye et al., Energy Procedia 16 (2012) 849.

12. L. Zheng, Int. J. Nucl. Energy Sci. Eng. 32 (2013) 32.

13. I.D. Abdelrazek, M.N. Aly, A.A. Badawi et al., Ann. Nucl. Energy 70 (2014) 36.

14. A. Elshahat, T. Abram, J. Hohorst et al., Int. J. Nucl. Energy 20149 (2014) 1. http://dx.doi.org/10.1155/2014/410715.

15. S.K. Moghanaki and M. Rahgoshay, Ann. Nucl. Energy 63 (2014) 302.

16. S. Dibyo, Susyadi and I.D. Irianto, Development of Pressurizer Model Using RELAP5, Proceeding of the National Conference on Nuclear Energy Technology (2014) 869. (in Indonesian)

17. L. Lixin and Z. Limin, Int. J. Nucl. Energy Sci. Eng. 32 (2013) 32.

18. Anonymous, RCS And Connected System, AP1000 Design Control Doc Rev.1, European $D C D$, EPS-GW-GL-700 Westinghouse (2009).

19. T. Pirasaci and D.Y. Goswami, Appl. Energy 162 (2016) 644.

20. Y. Zhang, T. Lu, P.X. Jiang et al., Ann. Nucl. Energy 90 (2016) 212. 